SEFARAD, vol. 80:1, enero-junio 2020, págs. 137-172

ISSN: 0037-0894, https://doi.org/10.3989/sefarad.020-005

\title{
La diáspora sefardí en Túnez: de finales del siglo XV a mediados del siglo XVIII*
}

\author{
Houssem Eddine Chachia** \\ Universidad de Sfax (Túnez) \\ ORCID ID: https://orcid.org/0000-0002-7702-8496
}

Este artículo revisa la historia de los judíos sefardíes en Túnez, conocidos también por los nombres de grana, liorneses o portugueses. En la primera parte, presentamos el estado de la cuestión de la historiografía relativa a los sefardíes tunecinos. A continuación, investigamos los itinerarios de los sefardíes que fueron expulsados a Túnez. Se puede hablar de dos principales itinerarios: el primero, de los que marcharon a Túnez después la expulsión de España y de Portugal a fines del siglo XV y principios del XVI; el segundo, de los que llegaron al país en el siglo XVII principalmente desde Livorno. Por último, estudiamos los diferentes aspectos del asentamiento de los sefardíes en Túnez, es decir, la llegada de los expulsados al país y la posición del Estado Hafsí y los beyes; sus relaciones y comunicaciones sociales y económicas con la mayoría musulmana, los moriscos, y los judíos locales (tuansa). Este estudio se basa en una rica bibliografía sobre los judíos tunecinos en general, además de otras fuentes: principalmente, el diario inédito de fray Francisco Ximénez, pero también otros textos españoles, así como documentos producidos por la comunidad portuguesa junto con algunas fuentes tunecinas locales.

Palabras Clave: Judíos portugueses en Túnez; grana; tuansa; relaciones étnicas; deportación; relaciones judeo-musulmanas.

The Sephardic Diaspora in Tunisia: From the end of the 15th Century to the Middle of the 18Th CenturY.- This article tries to study the history of Sephardic Jews in Tunisia, also called by the names of "Grana", "Livorno" or "Portuguese". In the first part we have tried to do a state of question to the historiography about Tunisian Sephardim. Then, we searched the itineraries of Sephardic Jews who were expelled to Tunisia. There were two main itineraries: the first one, that of those who went to Tunisia after the expulsion from Spain and Portugal at the end of the 15th century and the beginning of the 16th century; the second one, that of those who came to the country in 17th century mainly from Leghorn. Thirdly, we have tried to study the different aspects of

* Mi profundo agradecimiento al profesor Antonio Irigoyen López por sus correcciones, comentarios y consejos con respecto a este estudio.

**h.chachia@flshs.u-sfax.tn

Copyright: (C) 2020 CSIC. Este es un artículo de acceso abierto distribuido bajo los términos de la licencia de uso y distribución Creative Commons Reconocimiento 4.0 In- 
the Sephardic settlement in Tunisia, that is, the arrival of those expelled to the country and the position of the Hafsi State and the Beys, their social and economic relations and communications with the Muslim majority, the Moriscos, and the local Jews (Tuansa). This study has based on a rich bibliography about Tunisian Jews in general, in addition to multiple documents and sources, that is, mainly the unpublished diary of Fray Francesco Ximénez, as well as other Spanish sources; the documents produced by the Portuguese community, and some local Tunisian sources.

Keywords: Portuguese Jews in Tunisia; Grana; Tuansa; Ethnic relations; Deportation; Jewish-Muslim relations.

\section{EsTADO DE LA CUESTIÓN}

A pesar del número importante de estudios dedicados a la presencia de los judíos en Túnez, que se remontan a los finales del siglo XIX, como el libro de David Cazès ${ }^{1}$, podemos observar que la mayoría de las investigaciones están caracterizadas por la marginalización de la presencia judía en la Baja Edad Media y la Edad Moderna, pues, para este período histórico, no hemos encontrado más que algunos trabajos sobre los judíos en el Estado hafsí ${ }^{2}$, el libro de Jacques Taïeb, que trata la historia de los judíos del Magreb en la época moderna ${ }^{3}$, además del estudio de Maurice Eisenbeth, acerca de Argelia y Túnez desde $1516^{4}$.

Por consiguiente, la mayoría de los estudios han tratado la presencia judía desde principios del siglo XVII o -en el mejor de los casosdesde finales del siglo XVI, como, por ejemplo, el artículo de Robert Attal, sobre el aspecto económico de la vida de los judíos en Túnez desde fines del siglo XVI hasta el siglo XVIII ${ }^{5}$, o los trabajos de Jacques

${ }^{1}$ David CAzÉs, Essai sur l'histoire des Israélites de Tunisie (Paris: Durlacher, 1889).

2 Ibrahim JADLA, «Les juifs en Ifriqiya à l'époque hafside», en Histoire communautaire, histoire plurielle: la communauté juive de Tunisie (Tunis: Centre de publication universitaire, 1999) págs. 145-151.

3 Jacques TAї̈B, Sociétés juives du Maghreb moderne, 1500-1900: un monde en mouvement (Paris: Maisonneuve et Larose, 2000).

${ }^{4}$ Maurice Eisenbeth, «Les juifs en Algérie et en Tunisie à l'époque turque (15161830)», Revue Africaine 96 (1952) págs. 114-125.

5 Robert AtTal, La vie économique des Juifs de Tunis de la Fin du Xvie siècle au début du XVIIIe siécle à la lumière des archives du Consulat de France (Jerusalem: The Hebrew University and The Ben-Zvi Institut, 1974). 
Taïeb ${ }^{6}$ y Abdelhamid Larguèche ${ }^{7}$ sobre la época de la dinastía husaynita, a saber, desde 1705 hasta el siglo xIX. Además de la tesis de Ridha Ben Rejeb, donde el autor ha tratado los papeles económicos de los notables judíos ${ }^{8}$.

A pesar de la importancia de estos estudios en el tratamiento general de la historia de los judíos en el Túnez moderno, lo que nos interesa principalmente en este artículo es un grupo especial de esta comunidad: el grupo de los sefardíes, aquellos que a menudo eran conocidos con diferentes nombres, como los liorneses o -como encontramos en los documentos de archivo tunecinos- en árabe, al-Grana; en hebreo, legornim, goranim, y en francés, «la nation juifs portugaise» ('la nación judía portuguesa') o «la communauté juive portugaise de Tunis» ('la comunidad judía portuguesa de Túnez') ${ }^{9}$.

En la mayoría de los casos, los investigadores han tratado la presencia de la comunidad de liorneses en Túnez, ya sea como parte de un estudio general de esta presencia en el Mediterráneo -como el libro de Lionel Levy ${ }^{10}$, o en el Norte de África -como los estudios de Jean Pierre Filippini ${ }^{11}$ y Richard Ayoun ${ }^{12}$, o en un marco especial, como el artículo de este último sobre las actividades comerciales de los liorneses

${ }^{6}$ Jacques TAÏ̈B, «Réalité et perception de la condition juive en Tunisie, 1705-1857: un modèle maghrébin», en Juifs et musulmans en Tunisie: fraternité et déchirements, ed. Sonia Fellous (Paris: A. Somogy, 2003) págs. 123-129.

7 Abdelhamid Largueche, Les ombres de la ville: pauvres, marginaux et minoritaires à Tunis (XVIIIème et XIXème siècles) (Manouba: Centre de publication universitaire, 1999).

${ }^{8}$ Ridha Ben Rejeb, Los judios cortesanos y los judios del dinero en Túnez otomana (Beirut: Dar al-Madar al-Islami, 2010 [en árabe]).

9 Archivos Nacionales de Túnez, Serie D, Carton. 220, Dossier 21, y Serie H, Carton. 64, Dossier 776 .

${ }^{10}$ Lionel Levy, La communauté juive de Livourne: Le dernier des Livournais (Paris: L'Harmattan, 1996).

11 Jean Pierre FilIPPINI, «Livourne et l'Afrique du Nord au Xvinème siècle», Revue d'Histoire maghrébine 7-8 (1977) págs. 125-149.

12 Richard Ayoun, «Les juifs livournais en Afrique du Nord», La Rassegna Mensile di Israel 50:9-12 (1984) págs. 650-406: 655-657. 
en Túnez a finales del siglo XVII ${ }^{13}$, y los trabajos de Jacques Taïeb sobre los aspectos demográficos y onomásticos ${ }^{14}$.

Los aspectos culturales y sociales de la comunidad sefardí en Túnez apenas han recibido atención $\mathrm{y}$, si acaso, casi siempre han suscitado interés en el marco de la comparación con la comunidad judía local, los tuansa, tal y como ha tratado Attal en su artículo sobre los portugueses o liorneses, de una parte, y los tuansa, de otra ${ }^{15}$, o encontramos en el libro de Itshaq Avrahami ${ }^{16}$.

Todo esto no niega el intento de algunos autores por dedicar artículos o libros enteros a los judíos portugueses tunecinos, como es el caso del estudio de Elia Boccar ${ }^{17}$ o el libro de Attal y Joseph Avivi ${ }^{18}$, además del interesantísimo trabajo de Itshaq Avrahami ${ }^{19}$, y el libro de Lionel Levy $^{20}$.

${ }^{13}$ Richard Ayoun, «Le commerce des juifs livournais à Tunis à la fin du Xvire siècle», en Tunis, cité de la mer, ed. Alia BACCAR-Bournaz (Tunis: L'Or du temps, 1999) págs. 203-214.

14 Jacques TAї̈B, «Les Juifs livournais de Tunis: démographie et anthroponymie historiques», Revue du cercle de Généalogie juive 95 (2008) págs. 14-19 y «Les juifs livournais de 1600 à 1881», en Histoire communautaire, histoire plurielle: la communauté juive de Tunisie (Tunis: Centre de publication universitaire, 1999) págs. 153-164.

15 Robert Attal, «Autour de la dissension entre Twansa et Grana», Revue des études juives 141:1-2 (1982) págs. 223-235.

16 Itshaq Avrahami, Des relations entre Twansa et Grana, un chapitre de l'émancipation des juifs de Tunisie (Ramat-Gan: Université Bar Ilan, 1974).

17 Elia BocCARA, «Fidélités, solidarités et déboires dans la communauté juive portugaise de Tunisie, 1710-1944», en Les communautés méditerranéennes de Tunisie (Tunis: Centre de publication universitaire, 2006) págs. 167-180.

18 Robert Attal y Joseph Avivi, Registres matrimoniaux de la communauté portugaise de Tunis aux XVIIIème et XIX ème siècles (Jerusalem: Ben Zvi Institute, tomo I, 1989 y tomo II, 2000) y «Deux registres de ketubot de la communauté juive portugaise de Tunis, XviIIe-XIxe siècles», Revue des études juives 147:3-4 (1988) págs. 403-408.

19 Itshaq Avrahami, El Memorial de la Comunidad Judía Portuguesa de Túnez. La Grana (1710-1944) (en hebreo) (Lod: Orot Yahadut ha-Magreb, 1997). Véase la reseña en francés a este libro en Lionel Levy, La Lettre Sépharade 27, en línea: <http://www. lalettresepharade.fr/home/la-revue-par-numero/numero-27/le-memorial-de-la-communauteisraelite-portugaise-de-tunis-les-grana-1710-1944---itshaq-avrahami> [consultado el 17/01/2019].

20 Lionel Levy, La nation juive portugaise: Livourne, Amsterdam, Tunis (Paris: L'Harmattan, 2001). 
A pesar de la importancia de los trabajos arriba citados, y sus referencias esporádicas a los orígenes españoles y portugueses de los liorneses o grana, solo unos pocos estudios hablan de manera directa sobre la presencia sefardí en Túnez o consideran la presencia de los judíos portugueses como una continuación de la diáspora sefardí en el Mediteráneo. De entre estos raros estudios cabe citar el libro del senador Ángel Pulido ${ }^{21}$. En él, el autor estudió brevemente el número de los sefardíes que se instalaron en Túnez y el grado de conservación de su especificad ibérica. Esta marginación de la presencia sefardí en Túnez, se va a repetir en la mayoría de los trabajos, como los de Michel Abitbol ${ }^{22}$ y Richard Ayoun ${ }^{23}$, y va en la misma línea la aportación de María Antonia Bel Bravo, quien no dedicó más que tres páginas para hablar de los sefardíes tunecinos ${ }^{24}$.

\section{LOS ITINERARIOS DE LOS SEFARDÍES QUE LLEGARON A TÚNEZ}

Como hemos mostrado más arriba, los estudios que han tratado la presencia de los sefardíes en Túnez, especialmente con respecto a finales de los siglos XV y XVI, son muy raros, y no especialmente bien documentados. Sin embargo, todo esto no nos impide presentar nuestro intento de estudio, especialmente sobre los períodos más oscuros de esta presencia, es decir, los itinerarios seguidos por los expulsados y su llegada a Túnez.

21 Ángel Pulido, Españoles sin patria y la raza sefardí (Madrid: Establecimiento Tipográfico de E. Teodoro, 1905).

22 Michel АвітвоL, «Juifs d'Afrique du Nord et expulsés d'Espagne après 1492», Revue de l'histoire des religions 1, Tome 210 (1993) págs. 49-90, y «Juifs, chrétiens et musulmans après l'expulsion d'Espagne: le cas Nord-Africain», Historia moderna 6 (1993) págs. 57-71.

${ }^{23}$ Richard Ayoun, «Le Judaïsme séfarade après l'expulsion d'Espagne de 1492, est-il un monde éclaté?», Histoire Économie et Société 2 (1991) págs. 143-158, y «Les établissements des Juifs en Afrique du Nord après l'expulsion des Juifs d'Espagne», en Cinco Siglos de Presencia Judia en América 1492-1992, eds. Mario E. CoHEN y Celina A. Lértora Mendoza (Buenos Aires: Sefarad, 2000) págs. 215-222.

${ }^{24}$ María Antonia Bel Bravo, Sefarad: los judios de España (Madrid: Sílex, 2006) págs. 318-320. 
Al igual de Marruecos y Argelia ${ }^{25}$, Túnez fue una plataforma de recepción "tradicional" a los judíos ibéricos, destacando las fuertes relaciones entre los judíos catalanes y tunecinos en el siglo XIV ${ }^{26}$, lo que propició que el país recibiera probablemente un notable número de los judíos que huyeron de la persecución en los reinos hispánicos a fines del siglo XIV. Igualmente, debemos referirnos a las intensas relaciones comerciales entre los judíos españoles y tunecinos en el siglo XV, pues, de la lista de los judíos valencianos que cita José Ramón Hinojosa Montalvo, encontramos seis comerciantes que estuvieron en Túnez en la segunda mitad del siglo ${ }^{27}$. Asimismo, el mismo autor nos informa sobre los comerciantes judíos tunecinos que tuvieron comercio con Valencia en el siglo XV, citando casi 23 nombres como, por ejemplo, el de Fahim Caxarí, que «envía en 1412 desde Túnez diversos productos a Francesc Pardo, converso de Mallorca en Valencia», o Abrahim, que en 1469 «vendió polvo de grana e hilo de Almería» ${ }^{28}$.

En cuanto a los itinerarios escogidos por los exiliados a Túnez, podemos mencionar dos caminos principalmente, a saber: de una parte, los que llegaron al país directamente desde España y Portugal, después de la publicación de los decretos de la expulsión, o pocos años después, es decir, tras su paso por otras ciudades magrebíes; y, de otra, aquellos que llegaron a finales del siglo XVI y a lo largo del siglo XVII, a través de Livorno y otras ciudades italianas y europeas.

${ }^{25}$ Sarah Leibovici, «La diáspora sefardí en África del Norte», en Diáspora sefardí, ed. María Antonia Bel Bravo (Madrid: Mapfre, 1992) págs. 189-212: 190-192.

26 Esther BenBassa, Historia de los judios sefardies: de Toledo a Salónica (Madrid: Abada, 2004) pág. 69.

27 Véase la lista completa en José Ramón Hinojosa Montalvo, «Migraciones, viajes y desplazamientos de los judíos en tierras valencianas», en Movimientos migratorios y expulsiones en la diáspora occidental, ed. Fermín Miranda García (Pamplona: Universidad Pública de Navarra, 2000) págs. 143-164: 161.

28 Véase la lista completa en José Ramón Hinojosa Montalvo, «Judíos extranjeros en el reino de Valencia durante la Baja Edad Media», Sefarad 70:1 (2010) págs. 69-115: 108-113. 
2.1. Primer itinerario: los que marcharon a Túnez tras la expulsión de España y de Portugal

El cronista español Andrés Bernáldez nos informa que, entre los expulsados del reino de Aragón, un número de sefardíes que embarcaron de los puertos aragoneses y catalanes eligieron Túnez como destino final:

Los de los reinos de Aragón é Cataluña embarcaron por los puertos de Cataluña é Aragón, é entraron por la mar, y muchos de ellos entraron en la Italia, é otros a tierra de moros al reino de Túnez é de Tremecén é otros reinos, donde su ventura los echaba ${ }^{29}$.

Mientras que esta información que nos presenta Bernáldez fue la única que nos ayuda a documentar que unos sefardíes marcharon a Túnez, ya sea inmediatamente después de la emisión del decreto de la expulsión o en siguientes pocos años, nuestra investigación en los fondos de Archivo General de Simancas nos llevó a encontrar un documento raro, fechado en octubre de 1495, acerca de un tal Ruy López de Medina, judío originario de Coria convertido al cristianismo, quien niega haber practicado el contrabando de cosas prohibidas en el tiempo de la expulsión a Túnez.

Don Fernando e doña Isabel, etc a vos Pedro Maldonado, nuestro juez de los bienes de los judíos en el obispado de Coria, salud e gracia, sepades que Ruy López de Medina, vecino de la villa de Cáceres, nos fizo relación por su petición que ante nos en el nuestro Consejo se ha visto, diciendo que al tiempo que por nuestro mandado los judíos salieron de estos nuestros reinos e él se fue al reino de Tunis e que no sacó ni pagó oro, ni plata, ni cosa vedada, en lo término para lo sacar e que después alumbrado de gracia del Espíritu Santo se convirtió a nuestra santa fe católica con su mujer e dos fijos (hijos) e dejó otros cuatro fijos cautivos, que le cautivaron los moros en que se vino a la dicha villa de Cáceres desnudo e muy pobre, en que algunas personas que le conoció dice que le ayudaron e socorrieron por vía de limosna con fasta diez mil maravedíes, de que compró ... de ropa e se vistieron él e su mujer e fijos, e que ágora requirió ante el escribano ante quien

29 Andrés Bernáldez, Historia de los reyes católicos D. Fernando y Doña Isabel (Sevilla: J. M. Geofrin, 1870) vol. 1, pág. 340. 
habéis fecho cierto proceso contra el que se le diese para guarda de su derecho ${ }^{30}$.

Gracias tanto al relato de Bernáldez, como al documento de Ruy López, podemos confirmar que un número de expulsados eligieron Túnez como destino temporal o final. Esto se puede mostrar también gracias a los itinerarios de algunos personajes sefardíes importantes como Jacob ben Chajim Ibn Adonijah, conocido por «el tunecino», quien salió de España a Túnez después el decreto de la expulsión, y luego, en 1510, marchó a Roma, Florencia y, finalmente, Venecia, donde murió cerca de $1538^{31}$. Asimismo, podemos citar a Abraham Zacuto, que fue uno de los más famosos personajes sefardíes. Nacido en 1450 en la ciudad de Salamanca, donde estudió medicina y astronomía, eligió después de la expulsión de España el destino más cercano, o sea, Portugal y, más concretamente, Lisboa, donde trabajó para el Rey y participó entre 1496 y 1497 en las preparativas del primer viaje de Vasco de Gama ${ }^{32}$. Después de que el rey Manuel I de Portugal decretara el 5 de diciembre de 1496 el decreto de expulsión ${ }^{33}$, Zacuto salió hacia Túnez, donde acabó en 1504 su obra más importante, el libro Séfer Yuhasin ${ }^{34}$. Más tarde, elegiría como destino final el centro del Imperio otomano, muriendo en Damasco después de $1510^{35}$.

30 Archivo General de Simancas, Cancillería. Registro del Sello de Corte, Leg.149510, 128. Mis agradecimientos a José Pascual Martínez y Vicente Montojo por la transcripción del manuscrito.

31 Para más detalles sobre la biografía de Jacob ben Chajim Ibn Adonijah y sus trabajos, véase la excelente introducción de Christian David en Jacob Ben CHAJIM IBN Adonisahs, Introduction to the Rabbinc Bible (London: Longmans, Green, Reader and Dyer, 1867) págs. 1-35.

32 Joseph PÉRez, Los judios en España (Madrid: Marcial Pons Historia, 2005) págs. 357.

33 Sobre el decreto y su contexto histórico, véase François Soyer, «King Manuel I and the expulsion of the Castilian Conversos and Muslims from Portugal in 1497: new perspectives», Cadernos de Estudos Sefarditas 8 (2008) págs. 35-49.

34 Eleazar GutwiRTH, «The Sefer Yuhasin and Zacut's Tunisian phase», Judaísmo hispano: Estudios en memoria de José Luis Lacave Riaño, ed. Elena ROMERo (Madrid: Consejo Superior de Investigaciones Científicas, 2002) vol. 2, págs. 765-777: 773, y Abraham ben Samuel Zacut, The book of lineage: or Sefer Yohassin, translated and edited by Israel SHAmIR (Tel Aviv: Zacuto Foundation, 2005).

35 Acerca de Abraham Zacuto y sus libros, véanse Marciano MARTín ManUEL, Abraham Zacuto, 'Astrólogo de Don Juan de Zúñiga' (Sevilla: Renacimiento, 2010); 
De los itinerarios de Jacob ben Chajim Ibn Adonijah y Abraham Zacuto, observamos la gran movilidad de los expulsados; una movilidad determinada por las condiciones de cada país o, en general, la situación geopolítica complicada del Mediterráneo de fines del siglo XV y principios del XVI. En el marco de esta movilidad, encontramos algunos sefaradíes que salieron, primero a Marruecos y Argelia, pero marcharon después a Túnez. Tal es el caso de Abraham Levy Bacrat, de origen mallorquín, que salió después la expulsión de España a Tremecén y, de allí, llegó a Túnez en 1507, donde acabó su libro Séfer ha-Zikaron ${ }^{36}$.

Los datos que tenemos hasta ahora no nos permiten determinar la importancia de este último itinerario, sino sólo decir que llegaron a Túnez después su paso por Marruecos, Argelia o, incluso, Libia, pero podemos suponer que este movimiento se limitó a un número reducido de expulsados, por lo que no fue un movimiento de grandes grupos.

En conclusión, podemos observar que importantes personajes sefardíes eligieron el destino tunecino, lo que indica ya el atractivo de este destino, ya la buena recepción de los expulsados en el país, especialmente en el caso de los notables sefardíes. Además de los itinerarios de los prestigiosos personajes que hemos citado arriba, la salida de los sefardíes desde los puertos de Aragón y Cataluña hasta Túnez, y los altos costos de este largo viaje -en comparación con el destino marroquí o argelino- muestra probablemente la buena situación económica de los que salieron hacia Túnez. No obstante, parece que el destino tunecino no fue en muchos casos el destino final de los notables sefardíes, lo que podemos explicar por el miedo de estos expulsados a la invasión española en el norte de África ${ }^{37}$, especialmente desde que las tropas de los

Joseph Jacobs IsaAc Broydé, «Zacuto, Abraham ben Samuel», en The Jewish Encyclopedia (New York and Londres: Funk and Wagnalls Compagny, 1901-1906) pág. 627, y GutwirTH, «The Sefer Yuhasin».

36 Sobre la obra de Abraham Levy Bacrat, véanse Cecil Roth, Encyclopaedia Judaica (New York: Macmillan, 1971) vol. 11, pág. 232; Bel Bravo, Sefarad, pág. 318; Jean Fontaine, Histoire de la littérature tunisienne: du XIIIe siècle à l'indépendance (Tunis: Cérès éditions, 1999) pág. 72; Robert BRunschvig, La Berbérie orientale sous les Hafṣides des origines à la fin du Xve siècle (Paris: Adrien-Maisonneuve, 1940) vol. 1, pág. 429, y David CAZEs, Notes bibliographiques sur la littérature juive-tunisienne (Tunis: Impr. internationale, 1893) págs. 234-236.

37 Imn Adonijahs, Introduction to the Rabbinc Bible, pág. 2. 
Reyes Católicos ocuparon Mazalquivir en 1505, Orán en 1509, Bugía y Trípoli en 1510, y no ocultaron su deseo de controlar la ciudad de Túnez. En nuestra opinión, el miedo de los notables sefardíes recién llegados a la ciudad de Túnez de caer en el cautiverio o la matanza, los empujó a emigrar de nuevo para alejarse de la amenaza española o, incluso, portuguesa $^{38}$.

\subsection{El segundo itinerario: los que marcharon a Túnez a través Livorno}

A pesar de que la mayoría de los investigadores confirman que la presencia de los liorneses en Túnez se remonta a finales del siglo XVI y principios del siglo XVII, la fecha de la primera aparición de un liornés en los documentos del consulado francés en Túnez, según Richard Ayoun, es el 16 de septiembre de $1609^{39}$. Pero es difícil determinar la presencia de emigrantes en Túnez. Como muestra Lionel Levy, a través los documentos publicados por Renzo Toaff en su libro La nazione ebrea a Livorno e a Pisa (1591-1700) ${ }^{40}$, muchos de los nombres liorneses que figuran en los documentos del consulado francés en la primera mitad del siglo XVII, los encontramos más tarde habitando en Livorno, como, por ejemplo, David Cardoso, y David y Abram Montesino, que estuvieron en Túnez en 1611, y en el mismo año, aparecen el primero en Livorno y los dos últimos en Pisa. También Judá Crespín, que estaba en Túnez en 1613, se encuentra en 1633 en Livorno desempeñando una alta función para el gran Duque ${ }^{41}$.

Esta movilidad de los liorneses y las dificultades para determinar su afiliación a la orilla norte o sur del Mediterráneo, la observó fray Francisco Ximénez ${ }^{42}$ en su descripción de la comunidad liornesa en Argelia

38 Gregorio Sánchez Doncel, Presencia de España en Orán, 1509-1792 (Toledo: Estudio Teológico de San Ildefonso, 1991) págs. 167-168.

39 Ayoun, «Les juifs livournais...», pág.154.

40 Renzo ToAfF, La nazione ebrea a Livorno e a Pisa (1591-1700) (Florence: Olschki, 1990).

41 Véase más ejemplos en Levy, La nation juive portugaise, págs. 227-228.

42 Fray Francisco Ximénez de Santa Catalina nació el 2 de diciembre de 1685, en el pueblo de Esquivias. Pasó al norte de África en 1717, en que llegó a Orán en su 
en 1719, que es válida también para la comunidad que habitaba en Túnez:

... estos son los más de Liorna; y todos cada vez mueren donde nacen; porque siempre andan viajando de una parte a otra y de un logar a otro, sin hallarse bien en parte alguna. ${ }^{43}$

De este modo, podemos decir que las llegadas individuales, o de familias, no pararon al largo del siglo XVII y principios del siglo XVIII, debido a la prosperidad económica que había conocido el país en la época, así como a la relativa tolerancia religiosa.

Los primeros indicios del comienzo de la constitución de la comunidad liornesa, grana o portuguesa en Túnez, se remontan al año 1634, pues encontramos en los documentos el nombre de Israel «el tunecino», liornés que ocupó un puesto influyente al servicio del Gran Duque ${ }^{44}$, cuyo apodo bien puede indicar que este liornés nació o -al menos-, vivió un largo tiempo en Túnez. Otros signos de la presencia estable de los liorneses en Túnez serían tanto la frecuencia de las actividades co-

camino a Argel. Allí quedó hasta 1720, año en el que viajó a Túnez, donde pudo realizar su proyecto de crear un hospital para los cautivos cristianos. Su residencia en Túnez continuó hasta 1735, fecha en la que volvió a España. Murió en Dos Barrios en 1758. Del viaje de Ximénez a Túnez conservamos cuatros obras, la más importante es su diario inédito que lleva por título El Discurso de Túnez, una obra de siete volúmenes, en la que escribió diariamente sus observaciones desde su llegada al país hasta su vuelta a España en 1735. Para más detalles acerca de Ximénez y sus obras, véanse Houssem Eddine Chachia, «Una nota sobre los cautivos ibéricos en Túnez (1724-1725), a través El diario del Fray Francisco Ximénez», Revue D'Histoire Maghrebine 154 (2014) págs. 49-62: 50-51; Miguel Ángel DE Bunes, «Una descripción de Túnez en el siglo XviII: el diario de Francisco Ximénez», Hesperia. Culturas del Mediterráneo 10 (2008) págs. 85-96; Mercedes García-Arenal, «Nota a las traducciones manuscritas de F. Ximénez en la Real Academia de la Historia», Al-Qantara 6 (1985) págs. 525-534; Hedi Oueslati, «Argel, según el diario inédito de Francisco Ximénez (1718-1720)», Sharq Al-Andalus 3 (1986) págs. 169-181, y Leïla Ould, Alger, une cité turque au temps de l'esclavage À travers le Journal d'Alger du père Ximénez, 1718-1720 (Montpellier: Presses universitaires de la Méditerranée, 2014).

43 Francisco XimÉnez, Viaje de Argel (Real Academia de la Historia, ms.9/6008) fol. $57 \mathrm{r}$, febrero de 1719 .

44 Levy, La nation juive portugaise, pág. 227. 
merciales de esta comunidad en el consulado francés ${ }^{45}$, como el aumento de las familias que habitaban la ciudad de Túnez ${ }^{46}$. Pero tenemos que esperar hasta el año 1710, cuando se declaró oficialmente la fundación de la comunidad portuguesa en Túnez y su estabilidad definitiva en el país.

\section{El ASENTAMiENTO DE LOS SEFARAdíES EN TÚNEZ}

\subsection{El asentamiento después 1492}

A pesar de lo expuesto más arriba acerca de los itinerarios de los sefardíes que llegaron a Túnez inmediatamente después el decreto de la expulsión, o en los primeros años posteriores, donde hemos podido documentar la llegada de algunos grupos sefardíes a Túnez, capital del Estado hafsí, la escasez de los datos o, incluso, su ausencia, especialmente entre los años 1490 y 1494, es decir, la época del reino de Abu Yahia Zakaria II, hace que sea difícil determinar la posición de las autoridades y los grupos musulmanas locales para con los expulsados. Pues, ¿había sido diferente la posición de las autoridades hafsíes en la persona del rey Abu Yahia Zakaria II, que no pasaba de los 18 años de edad, frente las olas de expulsados, de las posiciones de Abd al-Wadids en Tremecén o los wattásidas en Fez? Luego, ¿cuál fue la postura de los habitantes locales ante aquellos judíos ibéricos?

Sobre la posición de los habitantes locales, Richard Ayoun refiere el testimonio de un autor judío anónimo, que parece no fue sefardí, quien habla de los expulsados que se dirigieron a ciudades tunecinas, y confirma que algunos musulmanes los prohibieron entrar a estas ciudades, y que muchos sefardíes murieron en sus alrededores ${ }^{47}$.

45 Pierre Grandchamp, La France en Tunisie au XVIIe siècle: 1681-1700 (Tunis, J. Aloccio, 1930) vol. 9, págs. 52, 57-58 y 59.

${ }^{46}$ Lionel LeVy (La nation juive portugaise, págs. 330-33) contabiliza 74 familias en el siglo XVII.

47 Ayoun, «Argelia y Túnez», pág. 477. También acerca de la situación difícil de los sefardíes expulsados que fueron a Túnez, Denis CoHEn-TANnoudji (Les Enfants d'Yishmaël: Itinéraires séfarades maghrébins du Moyen Âge à nos jours [Paris: Hermann, 2010] pág. 75) cita erróneamente el testimonio de Yehuda 'Hayat que fue refu- 
En el mismo marco, podemos mencionar el documento de Ruy López, quien, como hemos señalado, salió para Túnez, y dijo que, de sus seis hijos, cuatro los habían cautivado los musulmanes, y que volvió con su esposa y sus hijos «desnudo y muy pobre» ${ }^{48}$. El testimonio de Ruy López plantea muchas preguntas: ¿Su sufrimiento y el de su familia, tuvo lugar en la ciudad de Túnez, o en su camino de vuelta a tierras españolas? ¿En qué medida se puede confiar en sus palabras, especialmente cuando el objetivo de su testimonio es negar que hubiera escapado con objetos de valor en la época de la expulsión?

A pesar de todas estas precauciones, pensamos que estos dos testimonios no reflejan una posición definitiva de los tunecinos ante los expulsados, sino que podría ser algo temporal, consecuencia de lo que podemos llamar "el choque del primer encuentro", el cual generó dudas y el miedo a que los expulsados portaran enfermedades y apareciesen epidemias. En esta etapa de recepción, la posición de los habitantes y el poder tunecinos no fue diferente de la posición de las otras ciudades magrebíes, incluso de la ciudad de Fez, que se considera como la capital de la diáspora sefardí en el Magreb ${ }^{49}$.

Esta postura no significaría un rechazo permanente a los expulsados, especialmente cuando la presencia judía en Ifriqiya era muy antigua. Además, el reducido número de los sefardíes que eligieron el destino tunecino no sería una amenaza al equilibro demográfico de la ciudad de Túnez. Por tanto, aunque la mayoría musulmana mirara con desconfianza a los judíos, ello no se tradujo a lo largo del siglo Xv -al contrario de la ciudad de Fez, por ejemplo ${ }^{50}$ - en una hostilidad extrema.

giado en Fez. Véase el testimonio completo de Yehuda 'Hayat en Javier CASTAÑo GonzÁLEZ, «Traumas individuales en un mundo trastornado: El éxodo mediterráneo de R. Yehudah b. Ya aqob Hayyat (1492-1496)», en Movimientos migratorios y expulsiones en la diáspora occidental, ed. Fermín Miranda García (Pamplona: Universidad Pública de Navarra; Gobierno de Navarra-Departamento de Educación y Cultura, 2000) págs. 55-69.

48 AGS, RGS, LEG, 149510,128.

49 CAstaño González, «Traumas individuales», pág. 62.

50 Acerca de la masacre de los judíos de Fez en 1464, dice Andrés Bernáldez (Historia de los reyes, vol. 1, págs. 348-349): «Podéis saber, que en el reino de Fez, y en la ciudad mesma ovo anexamente muchos judíos, así como acá en España, ca se hallaban más de cien mil vecinos, é también fueron robados é muertos no ha muchos 
Con respeto a la posición de las autoridades hafsíes -en especial de Abu Yahya Zakariya (1490-1494) y Abu-Abd-Al-lah Muhàmmad V (1494-1526)-, consideramos que no fue diferente a la de otras autoridades magrebíes: buena acogida o, al menos, tolerancia con los expulsados. El derecho islámico, además, permite la presencia de judíos y cristianos en las tierras musulmanes, bajo el estado de dhimmi ${ }^{51}$, y el interés económico exigía una buena acogida a estos nuevos dhimmies, quienes tendrían que pagar la yizia (impuesto per cápita) y, con ello, aumentarían los recursos financieros del estado ${ }^{52}$, que estaba saliendo de las guerras de sucesión, después de la muerte de Abu-Amr Uthman en $1488^{53}$.

Así, creemos que esta política garantizó a la comunidad judía una situación de seguridad o estabilidad relativa ${ }^{54}$, lo que podría corroborarse en la ocupación de algunos judíos en funciones importantes en el

años, como en Castilla, todos en un tiempo- Ovo un judío, que llamaron Aaron, sabio muy sotil, que privaba mucho en demasiada manera con el Rey de Fez, en manera, que él regía y mandaba en el reino cuanto él quería, de lo cual los moros eran muy mal contentos, los que algo vallan, é alborotaron el común contra el Rey y contra los judíos, y levantóse el común de Fez, y mataron al Rey y al privado Aaron, é Matan ios modende entraron en las juderías, donde había en la ciudad más de dos mil casas, y metiéronlas á espada, y mataron é robaron, y no dejaron más de los que decían que querían ser moros». Véase también Muhammad IBN IBrĀHĪM ZARKASHĪ, Tārīkh al-dawlatayn alMuwaḥhidìyah wa-al-Hafșiyah (Tunis: al-Maktabah al-'Atīqah, 1998) págs. 311-312.

${ }^{51}$ Robert Brunschvig, Deux Récits de Voyage inédits en Afrique du Nord au xve siècle, Abdalbasit B. Halil et Jean Adorne (Paris: Larose, 1936) pág. 192. Dice Aduran acerca de los judíos en la segunda mitad del siglo Xv que «tenían un vestido especial, deferente al vestido de los musulmanes. Si no llevan ese vestido distintivo, estarán sujetos a abusos. Se ponen un trapo de tela amarilla en la cabeza o el cuello».

52 Especialmente a la luz de la multiplicación de gastos del Sultán Hafsid Abdullah Mohammed al-Mutawakil, como refiere León el Africano: «Tengo que decir que este rey es experto en extraer dinero de sus súbditos, dando algunos a los Alárabes (tribus) y gastar el resto para construir sus palacios»; León EL AfricANo, Wașf Ifrìqūyā (Beirut: Dār al-Gharb al-Islāmīyah, 1983) vol. 2, pág. 81.

53 Después de la muerte de Abou Amr Uthman en 1488, muchos de los parientes del príncipe heredero Abû Zakariyâ' Yahyâ al Massoued declararon la revolución, pues el nuevo Sultán asesinó a su tío Abû Baker, el gobernador de Trípoli, y cegó los ojos de su hermano Hussain, pero su primo Abd al Muemen tuvo éxito al derrotarlo en 1489. Abd al Muemen no gobernó más que un año, al ser derrotado por Abû Zakariyâ' Yahyâ, que gobernó hasta 1494, fecha en que murió de peste. De 1494 hasta 1526, gobernó Abû 'Abd Allâh Muhammad IV al-Mutawakkil.

${ }^{54}$ Brunschvig, La Berbérie orientale, pág. 398. 
Estado. León el Africano, por ejemplo, al referir su visita a Túnez a principios del siglo XVI, señalaba que era un rico judío quien usualmente desempeñaba el puesto del director de Aduanas ${ }^{55}$.

Con todo, quizás lo que mejor confirma esta actitud abierta frente los expulsados, es -como hemos mencionado arriba- que Túnez fuera elegida por destacados personajes sefardíes en los primeros años del siglo XVI, como, por ejemplo, Abraham Zacuto, Chajim Ibn Adonijah y Abraham Levy Bacrat. Aunque el país no fuera más que solamente una escala en su camino hacia otros destinos, esta elección confirmaría la situación relativamente cómoda que tenía la comunidad sefardí.

Con respecto a la estrategia del asentamiento de los nuevos llegados, podemos suponer que la mayoría habrían habitado en la ciudad de Túnez, en el mismo sitio ocupado por los judíos locales y los judíos que fueron llegados en 1391, es decir, el barrio judío de la Medina o la Hara $^{56}$. Por eso, ni León el Africano, ni Mármol Carvajal hablan en su descripción de la ciudad de Túnez de un barrio o elemento sefardí diferente al de los judíos locales, al contrario de sus descripciones a la ciudad de Fez, donde sí especifican la diferencia entre los grupos de judíos locales y los sefardíes ${ }^{57}$.

Al contrario de nuestra opinión, Jacques Taïeb se plantea la posibilidad de que los expulsados hubieran habitado fuera de la Hara, presentando como argumento la presencia de una sinagoga de la comunidad portuguesa en 1710 en el barrio de Al-Morjan, cerca de Bab Bhar, llamado Jama' Al-Yahud ('la mezquita de los judíos'), que en su opinión se remonta a la llegada de los primeros sefardíes en el final del siglo XV y los primeros años del siglo XVI ${ }^{58}$.

55 El Africano, Was f Ifrīqūyā, pág. 80, y Luis del Mármol Carvajal, Libro Tercero y segundo volumen de la Primera parte de la descripcion general de Affrica (Granada: Casa de Rene Rabut, 1573) fol. 91r-v.

56 Más detalles acerca de la Hara en Colette Bismuth-JARrassé y Dominique JARRASSÉ, Synagogues de Tunisie: monuments d'une histoire et d'une identité (Le Kremlin Bicêtre: Éd. Esthétiques du divers, 2010) págs. 71-87, y Paul Sebag y Robert AtTaL, L'évolution d'un ghetto nord-africain. La Hara de Tunis (Paris: PUF, 1959).

57 El Africano, Wașf Ifrīqūyā, vol. 1, pág. 284.

58 TAÏ̈B, «Les juifs livournais de 1600 à $1881 »$, pág. 157. 
A pesar de la ausencia de cualquiera prueba que confirmase que esta sinagoga fue solamente para la comunidad sefardí, o que su fundación se remonta a la época de la llegada de la primera ola de expulsados, e incluso si asumimos que fue una sinagoga exclusivamente del rito portugués, creemos que las autoridades no habrían permitido a los expulsados construir un nuevo barrio judío, fuera del espacio tradicionalmente dedicado a los judíos, un espacio bien limitado y conocido desde el siglo VI.

\subsection{El asentamiento de la comunidad portuguesa (los liorneses o el grana)}

Si la falta de datos no nos permite conocer perfectamente la estrategia de asentamiento de las autoridades hafsíes frente la primera ola de los expulsados sefardíes a fines del siglo XV y principios del siglo XVI, gracias al aumento de informaciones en el siglo XVII y especialmente la primera mitad del siglo XVIII, podemos conocer mejor la política de las autoridades otomanas en Túnez frente la segunda ola de expulsados.

La mayoría de los estudios sobre la comunidad portuguesa en Túnez han tratado el aspecto comercial de esta comunidad, y no han dado importancia a los aspectos sociales y culturales; así nos ocuparemos de los factores y circunstancias del asentamiento de los portugueses en Túnez, tratando de responder a las siguientes cuestiones: ¿Se puede hablar de continuidad entre la primera y la segunda olas de expulsados? ¿Hay una relación entre el asentamiento de los moriscos en Túnez y el asentamiento de los portugueses? ¿Cómo fueron las relaciones de la comunidad portuguesa con las autoridades tunecinas, la mayoría musulmana y los judíos locales?

El investigador tunecino Ridha Ben Rjab explica el importante número de portugueses en Túnez en los siglos XVII y XVIII y la prosperidad comercial de esta comunidad por la continuidad entre la primera ola y la segunda ola de expulsados; así, los judíos de origen ibérico habrían facilitado la integración de los portugueses en el tejido social y económico del país ${ }^{59}$. Sin embargo, varias razones nos impiden aceptar este

\footnotetext{
59 Ben Rejeb, Los judios cortesanos, pág. 50.
} 
punto de vista. Primero, a lo largo del siglo xv, y a partir de los datos de que disponemos hasta ahora, no podemos hablar de actuaciones destacadas en la economía tunecina por parte de individuos o grupos sefardíes de la primera ola. Además, las pocas fuentes y documentos de la segunda mitad del siglo XVI nos hablan de una tensa relación entre los sefardíes y los judíos locales.

A pesar de la relativamente buena situación de la comunidad sefardí en el primer tercio del siglo XV, sucesos como la inestabilidad política tras la muerte del sultán hafsí Abû 'Abd Allâh Muhammad al-Mutawakkil en 1526, los conflictos entre sus hijos por el trono, la dura política del nuevo sultán Mulay al Hassan (1526-1543), con la revuelta de muchas regiones, y su derrota frente los turcos y Hayreddin Barbarossa en 1534, y, por último, el saqueo de la ciudad de Túnez, después de la conquista de la ciudad por Carlos $\mathrm{V}$ y sus tropas, tuvieron un impacto muy negativo en la comunidad judía tunecina, que sufrió -como el resto de comunidades-, la matanza y el pillaje de las tropas del Emperador, como señala Joseph Ha-Kohine:

El emperador Carlos fue a guerrear a Túnez, que está en Berbería, y se apoderó de ella 21 de julio del año 5295 (1535). Perdió Túnez todo su esplendor en aquella época. Los judíos que se encontraban allí en gran número huyeron algunos al desierto, con hambre, sed y penuria, y los alárabes los despojaron de todo lo que habían sacado fuera. Muchos murieron en aquella época; algunos fueron pasados a filo de espada cuando entraron los incircuncisos en la ciudad; otros fueron cautivados por el enemigo, sin que hubiese nadie que los salvara en el día de cólera divina. Rabí Abraham, de allí (Túnez), ha escrito en sus obras todas las adversidades que soportaron, diciendo estas cosas: "aquí la tierra ha tragado a algunos de los nuestros, allá ha mandado a otros la espada; otros murieron de enfermedad y sed ..." ${ }^{60}$.

Estos acontecimientos nos llevan a cuestionar la continuidad y la importancia de la comunidad sefardí en Túnez después 1535, especialmente con la reproducción de las tensiones y conflictos entre los miembros de la familia hafsí por el poder, además de la crisis financiera sofocante que sufrió el país, a causa de la acumulación de deudas que

60 Joseph HA-KoHEN, El valle del llanto ('Emeq ha-Bakha), eds. y trads. Francisco Cantera Burgos y Pilar León Tello (Barcelona: Riopiedras, 1989) pág. 136. 
habían contraído los sultanes hafsíes para pagar a los españoles ${ }^{61}$. Todo esto arroja una sombra sobre la presencia judía, en general, en Túnez, $\mathrm{y}$, en particular, sobre la conservación de la comunidad sefardí de su identidad ibérica respecto a los judíos locales o tuansa.

Aunque excluimos la teoría de la importancia del factor de continuidad entre la primera ola de los refugiados sefardíes y la segunda ola en la instalación de la comunidad portuguesa en Túnez, sobre la base del mismo origen ibérico, pensamos que la importancia de este origen se puede relacionar con la comunidad morisca. Pues el factor alentador para la instalación de los liorneses en Túnez no fue «la existencia de contrapartes de judíos de origen ibérico» ${ }^{62}$, sino la existencia de contrapartes moriscos de origen ibérico. En nuestra opinión, no fue casual que el comienzo y la consolidación de la presencia de esta comunidad coincidiera con lo que se puede llamar "el siglo morisco en Túnez".

En este sentido, Lionel Levy muestra, a través los archivos del consulado francés en Túnez, la existencia de colaboración comercial entre los moriscos y los liorneses, considerando que esto constituye una prueba de la confianza entre las dos comunidades. De estas fuentes documentales se pueden citar un documento de 18 de enero de 1619, entre Mostaffa Barragan Andalou y Moise Israel, y un documento de 29 de abril de 1619, donde encontramos a un grupo de comerciantes moriscos testificando en favor de algunos sefardíes; también en un documento de 1624, un morisco del pueblo de Soliman, llamado Ally Ferraro, testifica en favor de un comerciante judío ${ }^{63}$.

${ }^{61}$ Esta crisis, resultado de la frágil situación política, militar y económica, fue fruto de la cantidad enorme de dinero que las autoridades hafsíes tenían que pagar a los españoles, en virtud del Tratado de 6 de agosto de 1535 y el tratado de Bona, firmado el 12 de agosto de 1535. Por ellos, los hafsíes tuvieron pagar 58000 dinares, además de un monto anual estimado en 20000 dinares. Para más detalles, véase Houssem Eddine Chachia, «Dos documentos inéditos entre Muley Alhacen al Hafsí y el rey de España Carlos V» [en árabe], Revue D’Histoire Maghrebine 151 (2013) págs. 411-425: 421.

62 Ben Rejeb, Los judios cortesanos, pág. 50.

${ }^{63}$ Levy, La nation juive portugaise, págs. 69-70. 
Esta cooperación comercial entre las dos comunidades y el conocimiento del mismo idioma (el español ${ }^{64}$ ), e incluso las mismas costumbres ibéricas, serían factores que facilitaron la instalación de la comunidad portuguesa o liornesa en Túnez, como si la presencia de los moriscos en la sociedad tunecina hubiera creado un ambiente acogedor, parecido al ambiente ibérico. Así, la presencia liornesa en Túnez pasó de temporal a estable y permanente, facilitada por una política oficial receptiva hacia una comunidad activa, que tenía un importante impacto en la economía del país, en general, y, especialmente, en las cajas de los beyes. Y es que, según los documentos de waqef, parece que el bey Hamuda Pecha, ordenó la construcción de viviendas al lado de la hara (el barrio judío), y los puso a disposición de los liorneses, quienes fueron obligados a alquilarlos a precios elevados ${ }^{65}$.

Tal vez todos estos factores explican la instalación de grana en Túnez al largo del siglo xVIII, pero la fecha oficial de la creación de la comunidad portuguesa en Túnez, o la instalación oficial, se remonta al año 1710. Aquí la pregunta es: ¿por qué esta fecha en particular?

Para responder a esta cuestión, se puede decir que la creación de la comunidad fue el resultado de la creciente del número de familias liornesas instaladas en Túnez, al ejemplo de las familias Medina, Asuna, Valenci, Lumbroso, Tapia etc. ${ }^{66}$ Además de este factor, nos parece que la creación de la comunidad portuguesa en Túnez hay que relacionarla con el papel que jugaron algunos personajes moriscos y liorneses poderosos, que tuvieron un lugar importante en el poder, y cuya palabra era oída por el bey Al-Husayn ibn Ali (1705-1735).

${ }^{64}$ Además del español había sefardíes que dominaban el italiano, el portugués, el francés y, por supuesto, el árabe.

65 Ahmed SaAdaoui, «Les Européens à Tunis aux xvire et xviIIe siècles», Cahiers de la Méditerranée 67 (2003 [en línea desde el 25/07/2005]) en <http://cdlm.revues.org/ index124.html $>$ [consultado el 17/02/2019].

66 Véase la lista de las familias más importantes instaladas a Túnez en BEN ReJEB, Los judios cortesanos, págs. 104-105. Asimismo, véanse otros nombres en Paul SeBaG, Les noms des juifs de Tunisie: Origines et significations (Paris: Harmattan, 2002). 
Entre las personalidades moriscas, podemos citar principalmente al jaznadar (tesorero o ministro de finanzas) Mahmud Asraiyrī ${ }^{67}$, que fue el segundo hombre fuerte en el Estado de Al-Husayn ibn Ali, y que, probablemente, había desempeñado un papel importante en convencer al Bey para aprobar el establecimiento de la comunidad portuguesa ${ }^{68}$. Se le ha vinculado especialmente con quien -a decir de fray Francisco Ximénez-, probablemente fuera el primer presidente de esta nación: Gabriel de Mendoza ${ }^{69}$, a quien hallamos en 1724 con su hijo y el cónsul francés en una visita al jaznadar, que estaba enfermo ${ }^{70}$.

Precisamente, pensamos que Gabriel de Mendoza jugó el papel más importante en la creación oficial de la comunidad portuguesa y en el mantenimiento de su estatus privilegiado en el Estado del bey Al-Husayn ibn Ali. Nos informa Ximénez que Gabriel de Mendoza fue el doctor

${ }^{67}$ Mahmud Asraiyrī, conocido también como Mahamut Jasnadal, fue el jaznadar o el ministro de finanzas del bey Al-Husayn ibn Ali. Asgaiyer Ibn Yusuf lo considera el segundo hombre fuerte en el Estado: «Mahmud Asraiyrī al-Andalusí, fue el gobernador y responsable financiero, es el que manda y prohíbe en el reino de Al-Husayn ibn Ali, no conoce con él nada, y hay gente llegan hasta que decir: algunas veces el bey se va a la casa de Mahmud Asraiyrī para hablar con él». Una noticia que confirma también en 1725 el reverendo fray Melchor García Navarro: «... últimamente visitamos al Jasnadal, sidi Amunada, secretario y primer ministro del bey, hombre, sin lisonja, de talento no común, capaz de governar más dilatado reino. A su conducta ha debido su amo la conservación de veinte años en el mando; porque su arreglada y sagaz integridad tiene a los basallos contenidos y contentes»; IBN Yusuf, Al-Mašra' Al-Malakī, vol. 2, págs. 71-74; Melchor Garcia Navarro, Redenciones de cautivos en África (1723-1725) (Madrid: Consejo Superior de Investigaciones Científicas, Instituto Jerónimo Zurita, 1946) pág. 288.

68 Ben Rejeb, Los judios cortesanos, pág. 68. Este autor confirma que las autoridades reconocieron a la comunidad portuguesa alrededor de la mitad del siglo XVIII, basándose en una orden emitida por Ali ibn Al-Husayn ibn Ali Bey, fechada en 1765, sobre el nombramiento de funcionarios de la comunidad portuguesa. Sin embargo, pensamos que este reconocimiento se remonta a la formación oficial de la comunidad en 1710 o, al menos, al reinado de Hussein ben Ali. Francisco XIMÉnez (Discurso de Túnez, vol. 5, ms.9/6012, fol. 89v, jueves 2 de julio de 1722) por su parte, se refiere a la distinción entre la comunidad local y la comunidad portuguesa por las autoridades, ya que habla de pagar lo que llama «el gremio», una cantidad de dinero a favor del bey Al-Husayn ibn Ali en 1722.

69 Ximénez, Discurso de Túnez, vol. 6, ms.9/6013, fol. 60v, 17 de junio de 1724.
70 Ximénez, Discurso de Túnez, vol. 6, ms.9/6013, fol. 57v, 31 de mayo de 1724. 
personal del Bey, y que era el «defensor de los judíos de Portugal» ${ }^{71}$. Además, Ximénez cita a Mendoza en su diario en el mes de marzo de 1722 en el marco de su visita, con otros doctores judíos, al Hospital Trinitario de Túnez:

Por la tarde vinieron a visitarnos el Doctor Mendoza, el Doctor Veneciano, y el Doctor $\mathrm{D}^{\mathrm{n}}$ Joseph Carrillo ... todos tres son médicos. ${ }^{72}$

Estas visitas se repitieron más veces, por diversos motivos, como la visita de 9 de marzo de 1722, asociada a cierta polémica religiosa: «Vino a nuestro cuarto el Doctor Mendoza, se estuvo discursando con él sobre la religión de los judíos, y no se concluyó nada» ${ }^{73}$; o la visita de 13 marzo del mismo año ${ }^{74}$. Por su parte, el objeto de la visita de 30 de enero de 1724 fue la historia y los restos arqueológicos locales:

Me hizo relación el doctor Mendoza que en esta campaña había encontrado muchas ciudades arruinados, pero en ninguno de ellas había encontrado inscripciones, solo pedazo de muralla, columnas, cisternas ... Me dicho también que Soliman Chelbi que era renegado italiano ... en una oración leyendo un libro morisco que trata de historia, y en ella refería la fundación del Cairuán ${ }^{75}$.

De otra parte, Ximénez señala que la hija de Mendoza casó con un comerciante de los liorneses: "Ayer estuve a ver al Doctor Mendoza y darle la enhorabuena de una hija ... que ha casado con un Mercante llamado Salina» ${ }^{76}$. La última noticia acerca de Mendoza en el diario de Ximénez se remonta al 27 de octubre de 1726, cuando Ximénez y otros fueron «a ver al Doctor Mendoza que se va al Camp» ${ }^{77}$.

La importancia de Mendoza no aparece solamente en su puesto como doctor personal del Bey, sino también parece que fue un intermediario

71 Ximénez, Discurso de Túnez, vol. 4, ms.9/6011, pág. 32.

72 Ximénez, Discurso de Túnez, vol. 5, ms.9/6012, fol. 8r-v, 7 de marzo de 1722.

73 Ximénez, Discurso de Túnez, vol. 5, ms.9/6012, fol. 10r, lunes 9 de marzo de 1722.

74 Ximénez, Discurso de Túnez, vol. 5, ms.9/6012, fols. 11v-12r, viernes 13 de marzo de 1722.

75 Ximénez, Discurso de Túnez, vol. 6, ms.9/6013, fols. 7v-8v, 30 de enero de 1724.

76 Ximénez, Discurso de Túnez, vol. 6, ms.9/6013, fol. 128r, 4 de noviembre de 1724.

77 XImÉneZ, Discurso de Túnez, vol. 6, ms.9/6013, fol. 287r, 27 de octubre de 1726. 
entre el Bey y el Duque de Toscana, pues encontramos a Mendoza presente cuando el Bey recibió una carta del Duque:

Fue hoy el Cavallero Laparelli al Palacio del Bardo visitar al Bey, le presento una cosa de Medicinas muy buenas puestas en ella ... estaba allí presente el Doctor $\mathrm{D}^{\mathrm{n}}$ Gabriel de Mendoza su Medico judío portugués ... con ella le dio una carta que se las enviaba ... del gran Duque de Toscana ${ }^{78}$.

También, y para proteger los intereses comerciales de su comunidad dentro y fuera del país, Mendoza se preocupó por mantener buenas relaciones con los actores extranjeros más influyentes en el Estado del Bey, a saber, los cónsules, y más concretamente, el cónsul francés, con quien no solamente intercambió muchas visitas, sino también servicios. En el mes de junio de 1724, el cónsul pidió a Mendoza escribir un informe sobre la enfermedad del jaznadar ${ }^{79}$, probablemente en el marco de una lectura anticipada de la muerte del segundo hombre fuerte en el Estado, su impacto en la situación general del país y, esencialmente, en los intereses del cónsul.

Por todo lo anterior, podemos hablar de una parte de la notable posición del doctor Gabriel Mendoza en el Estado del bey Al-Husayn ibn Ali. Una importancia que contribuyó de manera directa, o indirecta, a la fundación de la comunidad portuguesa en Túnez y, en consecuencia, a la instalación final de esta comunidad en el país. De otra parte, podemos hablar - por utilizar un término actual-, de una especie de lobby moriscosefardí en Túnez, encabezado por Mahmud Asraiyrī y Gabriel de Mendoza. Dos personajes que ocupan los primeros puestos en el poder, hablan el mismo idioma, tienen el mismo origen ibérico y, probablemente, tienen los mismos intereses comerciales.

Este contexto favorable pudo haber sido la razón de que muchos sefardíes, ya fueran liorneses, conversos o marranos eligieran Túnez como segunda patria. Túnez -al igual que Marruecos ${ }^{80} \mathrm{y}$, en menor

78 Ximénez, Discurso de Túnez, vol. 5, ms.9/6012, fol. 71r, martes 26 de mayo de 1722.

79 Ximénez Discurso de Túnez, vol. 6, ms.9/6013, fol. 60v, 17 de junio de 1724.

80 Por ejemplo, XıмÉNez (Discurso de Túnez, vol. 5, ms.9/6012, fol. 16r, miércoles 11 de mayo de 1722) nos informa sobre un converso que volvió al judaísmo en Meknés: 
medida, Argelia-, fue un destino importante para los conversos que quisieron dejar el cristianismo y volver al judaísmo. En su diario, Ximénez nos informa sobre el caso de Joseph Carrillo, que fue uno de estos renegados:

También me ha venido a ver una vez Sr Joseph Carrillo que siendo religioso trinitario Descalzo, de la provincia de Castilla apostató de su religión, y se vino a Túnez donde se ha declarado judío, y se ha casado con una hija del Doctor Mendoza ... Aquí ha estudiado (Joseph Carrillo) el hebreo y se ha hecho Rabino ... ${ }^{81}$

A partir de estas noticias de Ximénez, podemos confirmar, una vez más, que Túnez, a comienzos del siglo XVIII, fue una tierra de acogida tanto para los sefardíes que habían estado en Livorno u otras ciudades italianas, como para los que estuvieron viviendo como cristianos en Portugal y España. El caso de Joseph Carrillo muestra que en Túnez existía una comunidad portuguesa muy organizada, por lo que fue un destino preferente para los refugiados sefardíes, y en especial, para sus personalidades más destacadas.

Joseph Carrillo, que fue un religioso cristiano en Castilla, encontró en Túnez, no sólo el sitio adecuado para volver al judaísmo, sino también para estudiar profundamente la religión judaica y la lengua hebrea, y ser capaz de mantener discusiones en la polémica religiosa:

Vinieron a mi cuarto el Doctor Mendoza y el Doctor $\mathrm{D}^{\mathrm{n}}$ Joseph Carrillo, este empezó a despuntar contra la religión Cristiana, defendiendo la mucha secta que enseña, que llama de los naturalistas, obstinado ...

\footnotetext{
«Un judío guiado de un cautivo valenciano, dijo que era Descalzo y que pocos meses que había venido de Mequinez con su mujer, que era natural de Granada y que quería ir a Lisboa para donde esta aprestada una Santana Iglesia ... dijo llamarse Juan Cárdenas y en el judaísmo Mardojaic, de edad de cuatro (?) años, natural de Granada, hijo de Juan Cárdenas y Magdalena Rodríguez, casado con Sesina de María de Pina, natural del Puerto de santa María, y en el judaísmo se llamaba Raquel, de edad de 50 años, poco más o menos, había consigo un niño, que dijo ser de edad de hasta nueve años, poco más o menos, preguntó cómo se llamaba, y dijo que Juan Antonio Vicente, preguntó si estaba bautizado el $\mathrm{Pr}^{\mathrm{r}}$ Lector Monaserio, y respondió que no, dijo estas circuncidado, y llamaría Samuel».
}

81 Ximénez, Discurso de Túnez, vol. 4, ms.9/6011, pág. 34. 
en su opinión ... y por su lengua habla mal desatinos y blasfemias que jamás he oído ${ }^{82}$.

Ximénez confirma este extremo en una nota de 7 de marzo de 1722:

Por la tarde vinieron a visitarnos el Doctor Mendoza, el Doctor Veneciano, y el Doctor $\mathrm{D}^{\mathrm{n}}$ Joseph Carrillo, este fue Religioso Bernardo, después Trinitario ... vino de España a Túnez a hacerse judío ...

Por todo lo anterior, podemos afirmar que la situación de la comunidad portuguesa en Túnez a principios del siglo XVIII era mucho mejor que la de la primera oleada de los sefardíes que llegaron a finales del siglo XV y comienzos del siglo XVI. Aunque las leyes de dhimmis (Gentes del Libro) determinaban la situación de esta comunidad en su relación con el poder o la sociedad tunecina musulmana, gracias a los importantes papeles que jugaron los notables sefardíes en el país, sus relaciones con extranjeros importantes, como los consulados y el Duque de Toscana, y sus relaciones con grupos locales, como los moriscos, y la cercanía de algunos miembros de la comunidad al poder, como el caso del doctor Mendoza, algunos pudieron superar los límites sociales de la situación de dhimmis y enriquecerse.

Con todo, los sefardíes tunecinos eran conscientes de que su evolución social estaba limitada por las leyes de dhimmis, y que su riqueza podría ser una razón para formar una opinión pública hostil a ellos, fundamentalmente en los tiempos de hambrunas y guerras. Por ello, los rabinos de la comunidad emitieron tacanot y escamot ('ordenanzas y aprobaciones') que prohibían a los miembros del grupo hacer ostentación de su riqueza ${ }^{83}$.

\section{LAS TACANOT Y ESCAMOT ESPAÑOLAS DE LA COMUNIDAD PORTUGUESA DE TÚNEZ}

Al contrario de muchos grupos sefardíes instalados en el mundo islámico, que sólo podían escribir su lengua española en letras hebreas, el

82 Ximénez, Discurso de Túnez, vol. 5, ms.9/6012, fols. 11v-12r, viernes 13 de marzo de 1722.

83 Levy, La nation juive portugaise, págs. 340-352. 
grupo sefardí de Túnez -al menos hasta el primer tercio del siglo XVIII-, tenía permitido escribir sus documentos españoles en letras latinas. Todo esto confirma la buena situación o el margen de libertad que tenía esta comunidad, resultado de la presencia morisca, como confirma Lionel Levi ${ }^{84}$. Es decir, que esta excepción sefardí en Túnez hay que relacionarla con la continuidad de la escritura del español en letras latinas por los moriscos hasta la primera mitad del siglo XVIII ${ }^{85}$.

Los documentos que vamos a tratar aquí son cinco tacanot y escamot, fechadas entre octubre de 1726 y marzo de 1759, publicadas por primera vez por Itshaq Avrahami, y vueltas a publicar en el anexo del libro de Lionel Levy. Los documentos manuscritos originales se conservan en el Instituto Ben Zvi, en Jerusalén ${ }^{86}$.

Estos documentos muestran casi dos siglos después de la expulsión de los sefardíes de España y Portugal la importancia del componente ibérico en la identidad de la comunidad portuguesa en Túnez. La emisión por los rabinos de estas órdenes o tacanot en español, confirma que el castellano seguía siendo el idioma de los sefardíes instalados a Túnez.

También acerca de la utilización del español por la comunidad portuguesa en Túnez, nos informa Ximénez quien en su visita al cementerio judío, el 29 de septiembre de 1721, había encontrado una única inscripción en castellano:

De aquí fui al cementerio de los judíos, las sepulturas estas cubiertas de ladrillo y en medio una pierda cuadrada con inscripción hebreo, solo

84 Levy, La nation juive portugaise, pág. 340.

85 Véanse los testimonios de Francisco Ximénez sobre la utilización del español por los moriscos. También en el mismo período de los documentos españoles de la comunidad portuguesa, encontramos un morisco llamado Mohamet el Tahager de Urrea, que tradujo del árabe al español dos libros: Budinar, Historia de Túnez, traducida del arábigo al español por Mohamet el Tahager de Urrea, siendo su amanuense Fr. Francisco Ximénez (Madrid: Real Academia de la Historia, 1727, ms.9/6015); Achmet GuACIR, Historia de Túnez, Traducción del árabe al español por Mohamet el Tahager de Urrea, De letra de fr. Francisco Ximénez (Madrid: Real Academia de la Historia, ms.9/6025); $c f$. Míkel De Epalza, «Nuevos documentos sobre descendientes de moriscos en Túnez en el siglo XVIII», en Studia historica et philologica (Roma: Instituto Español de Cultura, 1984) págs. 195-228.

${ }^{86}$ Instituto Ben-Zvi para el estudio de las comunidades judías de Oriente, n. ${ }^{\circ} 1878$; Levy, La nation juive portugaise, págs. 340-352. 
un encontré que tenía inscripción en lengua española, en mal carácter y con abreviaturas formada de esta forma: "Aquí iaxe sepultado es de Joseph de los gloriosos ej..$^{\circ}$ de Jacob Moissid (?) ... Murió a 3 de marzo de $1721 " 87$.

Acerca del contenido de estas tacanot y escamot parece que su emisión se debió a la mejora económica y social que parte de la comunidad portuguesa disfrutó bajo el Estado del bey Al-Husayn ibn Ali y -tal y como señalábamos más arriba - también influyó la hambruna que el país padeció en 1723. El contexto muestra que los portugueses, en comparación con los judíos locales (tuansa) o la mayoría musulmana, parecían gozar de una mejor situación, pues aunque Ximénez se refiere a la muerte de musulmanes y judíos locales por dicha hambruna, jamás habla de manera clara y directa de la muerte de miembros de la comunidad portuguesa, aun cuando Ximénez, por lo general, distingue entre los judíos portugueses y los judíos locales ${ }^{88}$.

\subsection{La relación de la comunidad portuguesa con las autoridades oficiales y la mayoría musulmana}

A través el análisis de los 77 puntos o capítulos de las tacanot y escamot hemos observado que acerca de 40 puntos tratan el tema de la conservación de la riqueza de la comunidad, es decir, la prohibición a los miembros de la comunidad -sobre todo a las mujeres-, de mostrar su riqueza en los espacios públicos, o en los espacios comunes con las otras comunidades.

Esta prohibición comprende especialmente la demostración de que los miembros de la comunidad tienen metales preciosos, específicamente

87 Ximénez, Discurso de Túnez, vol. 4, ms.9/6011, p. 378, 29 de septiembre de 1721.

88 Ximénez, Discurso de Túnez, vol. 5, ms.9/6012, fols. 205r-206v. Por ejemplo, Ximénez nos habla de la muerte por inanición de 11 judíos los días 25 y 26 de octubre de 1723, y que los musulmanes vinieron al hospital para pedir limosna: «Dijeron por cosa certa que se avén muerto 37. Moros de necesidad, y otra buena parte de judíos, por la grande hambre que ay en el país»; y en otra nota dice: «Se cayeron muertos cuatro judíos de necesidad. Los moros se van al hospital a pedir limosna, entran a la enfermería a cosos los huesos que arrojan los enfermos, para comer ... y a algunos ... da limosna, pero no a todos, porque no se puede». 
oro y plata. Por ejemplo, las mujeres sefardíes tenían prohibido llevar ropas doradas o con plata. También la primera tacaná precisa el número de joyas que podían lucir las mujeres fuera de la casa, mientras que la segunda tacaná les prohibía llevar ropas de seda ${ }^{89}$; por su parte, en el punto número 7 de la primera tacaná se dice:

... que no pueda vestir fuera de su casa cosas con joyas seto en la cabeza una sola xoya y sola par de arcadas con su cadenetas que susténtenlas arrecadas, y una sola xoya en el pecho y un par manillas, y dos anillos, y el quidusim esto la novia que puede salir con lo que quisiere en el primer año de cazada..${ }^{90}$.

La prohibición de mostrar la riqueza perseguía evitar que el Estado impusiera más impuestos o multas provisionales a la comunidad, en un momento en el que este pasaba por dificultades financieras, a causa de la guerra civil entre el bey Al-Husayn ibn Ali y su sobrino Ali Pacha ${ }^{91}$. Pero, en nuestra opinión, la prohibición buscaba no dar motivos para el resentimiento por parte de los habitantes de mayoría musulmana que estaban viviendo en la pobreza. Sólo en relación con los habitantes locales se puede entender el segundo punto de la tacaná de 1736, que prohibía a las mujeres liornesas ir al baño (hammam) o a casa de un musulmán llevando joyas o «vestimentas demasiadas» ${ }^{92}$.

La prohibición no comprendía solamente aspectos materiales, sino también aspectos culturales, probablemente con el objetivo de conservar la "pureza cultural" de la comunidad. Así, las tacanot y escamot prohi-

89 "Copia de las escamot que se hyizieron en el K.K. de portugueses En Tunes a 20 Tisri 5497 (25 septiembre 1736)», en Levy, La nation juive portugaise, pág. 345.

90 «Copia de las tacanot y escamot quitada del Libro antiguo de nuestro K.K. de Portugueses Tunes a 9 Tisri 5487 (14 octobre 1726)», en Levy, La nation juive portugaise, pág. 343.

91 Ximénez, Discurso de Túnez, vol. 5, ms.9/6012, fol. 89r, jueves 2 de julio de 1722. Sobre una de estas multas temporales dice Ximenez: «... el Bey toma de los judíos, que encontraron con las mugeres veinte mil pesos, y de otras muchas piensas por no mui grandes causal ha tomado estos días algunas cantidades a uno de ello, lleva seis mil, a otro cuatro mil, y lo demás lo paga todo el gremio de los judíos liorneses, sin aver pescado, esta es la justicia que se hace en esta tierra».

92 «Copia de las escamot quitada del Libro antiguo de nuestro K.K. de Portugueses Tunes a 20 Tisri 5497 (25 de septiembre de 1736)», en LeVy, La nation juive portugaise, pág. 343. 
bían a las mujeres portugueses organizar fiestas en sus casas en las que se usara el rebab, un instrumento de música local, así como bailar en las casas de musulmanes ${ }^{93}$.

Estas cuestiones muestran, de una parte, la existencia de fluidas relaciones sociales entre los miembros de la comunidad portuguesa y los de la mayoría musulmana, lo que niega la teoría del gueto, o que cada grupo estaba cerrado en su mundo. De otra parte, estas últimas tacanot y escamot revelan que los límites de la integración de los sefardíes en Túnez no solamente dependían de la religión, o la mirada negativa o discriminatoria de la mayoría musulmana hacia la minoría judía, sino también de los límites de comunicación que ésta había establecido respecto de los otros grupos. Las tacanot y escamot fueron muy estrictas en este asunto, pues cada vez se hacía mayor hincapié en lo que debía cumplirse o ser castigado o multarse, siempre con el objetivo de restringir lo más posible la aculturación, ya que había que preservar la especificidad cultural de la nación portuguesa, que representaba la columna vertebral del grupo y la base de su cohesión y distinción.

\subsection{La relación de la comunidad portuguesa con los judios locales (tuansa)}

Aunque compartían la misma religión judía, la relación entre la comunidad portuguesa y la comunidad local -como muestran diferentes investigadores ${ }^{94}$ - fue muchas veces tensa y conflictiva, como resultado de la diferencia cultural y económica, pues la prohibición de mostrar la riqueza no sólo se orientaba hacia la mayoría musulmana, sino también hacia los tuansa. Los líderes de la comunidad portuguesa tenían miedo también de la reacción de los judíos locales que estaban viviendo una situación económica relativamente difícil, al contrario de los liorneses

93 «Copia de las tacanot y escamot quitada del Libro antiguo de nuestro K.K. de Portugueses Tunes a 9 Tisri 5487 (14 octubre 1726)», en LEVy, La nation juive portugaise, págs.343-344, puntos 9 y 10.

94 De estos estudios véanse, precisamente, LargueChe, «La Communauté juive», págs. 165-180; ATTAL, «Autour de la dissension», págs. 223-235; TAї̈B, «Les juifs livournais de 1600 à 1881», págs. 155-158, y LevY, La nation juive portugaise, págs. 187-201. 
que habían acumulado una riqueza considerable en corto tiempo y se encontraban cercanos al poder, como fue el caso de Gabriel de Mendoza ${ }^{95}$.

Esta tensa relación y los límites de comunicación entre las dos comunidades judías en Túnez, se muestra claramente en la tacaná de 25 de septiembre de 1736, que prohíbe a los miembros de la comunidad portuguesa comprar ropa «ni de los musulmanes, ni de los judíos de la tierra» ${ }^{96}$. Estos límites se concretarán oficialmente pocos años después, en 1741, a través de la tacaná de Qasmet Diar al-Ham, que organizaba la compra de carne, y los impuestos que debía pagar cada comunidad, además de determinar la integración de los judíos que emigraban a Túnez, de tal modo que los judíos que venían de los países cristianos se integraban en la comunidad portuguesa, mientras que los judíos que venían del Magreb u Oriente se adscribían a la comunidad de los tuansa ${ }^{97}$.

En el mismo marco, el punto 16 del escamot de 1736 refleja el alto grado de conflictividad entre las dos comunidades, o al menos la visión de la comunidad portuguesa, la cual trata de la misma manera a los «Xudios de la Tierra» (los judíos locales) -a pesar de que comparten con ellos la religión y el espacio de habitación-, y a los musulmanes -pese a ser de otra confesión y habitar otros espacios-. En el mismo sentido, la tacaná de 1753 prohíbe a las judías portugueses mandar platos de dulces fuera de la casa, especialmente a las casas de los judíos locales ${ }^{98}$.

95 Ximénez, Discurso de Túnez, vol. 7, ms.9/6014, fol. 17r, 30 de abril de 1727, y fol. 329r, 26 de noviembre de 1732. A cambio de la importante posicion de Gabriel de Mendoza, el líder de la comunidad portuguesa, la posicion del presidente de la comunidad de los judíos locales, y según algunos datos presentados por Ximénez, no estaba al mismo nivel, especialmente porque los tuansa, al contrario de los portugeses, no fueron protegidos por el Duque de Toscana. Ximénez nos informa que en el mes de febrero de 1727, el Bey encarceló al presidente Joseph y otros miembros de la comuniodad. Asimismo, en 1732, el bey encarceló y multó al juez de los judíos.

96 Se refiere a los judíos locales con el término «Xudios de Tierra»; Levy, La nation juive portugaise, pág. 345 .

${ }_{97}$ Por más detalles sobre esta tacaná véase Ben Rejeb, Los judios cortesanos, págs. 65-66.

98 «Copia de las tacanot o sean escamot que se hyizieron en el K.K. de Portugueses de Tunes a 14 Adar Seni 5513(20 Mars 1753)», en LeVY, La nation juive portugaise, pág. 348. 
De aquí, y aunque estamos de acuerdo con el punto de vista de Ridha Ben Rejeb que opina que la causa del conflicto y la diferencia entre las dos comunidades fue principalmente económica ${ }^{99}$, pensamos que las diferencias sociales y culturales no fueron de menos importancia porque la prosperidad económica de la comunidad portuguesa fue resultado de la consolidación social y cultural de la comunidad, así como de la solidaridad de la diáspora sefardí en el Mediterráneo. Esta solidaridad se basaba principalmente en una historia común: la expulsión como un evento fundamental, el origen ibérico y el conocimiento de las lenguas española y portuguesa.

Además, la preponderancia de la causa sociocultural frente a la causa económica se consolida cuando se comprueba que se dio la misma situación de conflicto entre los sefardíes y los judíos locales en otros países. Aquí podemos citar la tensa relación entre los liorneses y los judíos locales en Ámsterdam. También tenemos el ejemplo de los megorašim (los sefardíes en Marruecos) y su conflicto con los tošabim (los judíos locales), donde dos rabinos locales, llamados Hayim Gaguin y Naguid Šem-Tob ben Abraham, emitieron una orden prohibiendo a los tošabim comprar carne a los carniceros de los megorašim, por no ser una carne kašer o apta para consumo ${ }^{100}$.

En el mismo sentido, y siempre sobre la importancia de la causa sociocultural, encontramos que muchos viajeros a Marruecos confirman que los sefardíes conservaban su especificad ibérica ${ }^{101}$. Podemos citar el testimonio del inglés John Brithwait, que visitó Marruecos entre 1727 y 1728, quien señalaba que:

\footnotetext{
99 Ben Rejeb, Los judios cortesanos, pág. 66.

100 АвітвоL, «Juifs d'Afrique du Nord», págs. 85-84. Dice el autor que el origen de este caso es un rabino de tuansa, llamado Šalom ben Masnot, que visitó Fez en 1500, quien criticó que los judíos locales hubieran adoptado el método de sacrificio traído por los desplazados, y los recondujo a su propia forma de matanza.

101 Haïm ZAFrani, «La vie intellectuelle juive au Maroc de la fin du xve siècle au début du XXe siècle», Revue de l'Occident musulman et de la Méditerranée 9 (1971) págs. 201-211: 207-208. Entre los más claros testimonios de la conservación entre los expulsados de sus costumbres ibéricas, y sus principales diferencias de los tošabim (judíos locales), se hallaba el mantenimiento de la prohibición de la poligamia hasta un siglo después de su llegada a Marruecos.
} 
la mayoría de los judíos son de las familias que fueron expulsados de España y Portugal ... y habían conservado hasta hoy su antiguo idioma lo que les facilita el comercio con los extranjeros en los puertos marítimos ${ }^{102}$.

De otra parte, hay mucha similitud entre la posición de la comunidad portuguesa en Túnez y su relación con los judíos locales, con la situación de la comunidad morisca respecto de los musulmanes. Pues, a pesar compartir la misma religión, también los moriscos tuvieron, en muchas ocasiones, conflictos con la mayoría musulmana, debido a la conservación de su especificidad cultural ibérica ${ }^{103}$. Por tanto, se puede aventurar que este origen ibérico permitió crear una relación especial entre la comunidad portuguesa y la comunidad morisca.

\subsection{La relación de la comunidad portuguesa con la comunidad morisca}

La tacaná de 8 de abril 1748 confirma nuestra teoría acerca la existencia de un lobby morisco-sefardí en Túnez pues, si la relación de Gabriel de Mendoza con Mahmud Asraiyrī, y probablemente Šerif al Castelli ${ }^{104}$ confirma la alianza política entre los dos grupos, esta tacaná confirma las relaciones sociales que existían entre las dos comunidades.

102 John Braithwaite, Histoire des révolutions de l'empire de Maroc, depuis la mort du dernier Empereur Muley Ismaël (Amsterdam: P. Mortier, 1731) pág. 81. Para más detalles acerca la conservación de megorašim de su especialidad cultural y su tensa relación con el tošabim, véanse Haïm ZAFRANI, «Las comunidades judías de origen ibérico de Marruecos desde 1492 hasta nuestros días», en Los judios de España: historia de una diáspora '1492-1992', ed. Henry Méchoulan (Madrid: Editorial Trotta, 1993 ) págs. 495-598, y BraithWAIte, Histoire des révolutions, págs. 431.

103 Más información en Houssem Eddine CHACHIA, «The Moment of Choice: The Moriscos on the Border of Christianity and Islam», en Conversion and Islam in the Early Modern Mediterranean: The Lure of the Other, ed. Claire NorTON (London: Routledge, 2017) págs. 19-154: 132-135.

104 Šerif Al Castelli aparece como un jerife morisco de la familia Contreas o Contreras, de Castilla, en concreto de Alcalá de Henares. Fue un comerciante muy rico y de los cercanos del bey de Túnez Al-Husayn ibn Ali. Además, fue el director de un hospital que estaba en la Medina de Túnez. Šerif Al Castelli se refugió en Trípoli en 1735 después la derrota de Al-Husayn ibn Ali ante el ejército argelino. El nuevo bey Ali Pacha le confiscó sus bienes y regresó a Túnez en 1756 con la vuelta de los hijos de 
Como las otras tacanot, esta prohibía a los miembros de la comunidad portuguesa, y especialmente a las mujeres, algunas costumbres y vestimenta, la mayoría de las cuales eran moriscas, como refiere directamente en los puntos uno y dos. En el primero se prohibía «que ninguna mujer pueda tener ninguno cabello de su cabessa en la frente que llaman los moriscos cofià ...» ${ }^{105}$; mientras que el punto numero dos prohibía utilizar el debga, que utilizaban las moriscas para embellecer sus cejas: «que no pueda ninguna mujer hacer ningunas pintas negras ni en la cara ni en las manos ni en los pies ni tinir las sexas que llaman los Moriscos debga»; además, el punto número tres prohibía a las portuguesas llevar una flor a su cabeza como las mujeres moriscas: «que ninguna mujer puede poner ninguna flor colgada sobre la cara eseto las flores que se acostumbra a poner en la cabeza» ${ }^{106}$.

Se puede deducir de esta tacaná, consagrada casi totalmente a la prohibición a las mujeres sefardíes de seguir las costumbres y ropa de las mujeres moriscas, la importante conexión intercultural y social que existía entre ambas comunidades. Una aculturación que, en nuestra opinión, no se limitaba solamente a las mujeres, sino que, igualmente, se extendía al resto de componentes de las dos comunidades, debido a su mismo origen y a compartir la cultura ibérica y el conocimiento del español.

\section{CONCLUSIÓN}

A la luz de todo lo anterior, y en el marco de la comparación entre la situación de los sefardíes antes y después de la expulsión, podemos decir que la posición de esta comunidad en la sociedad tunecina no fue diferente a la que tenían en la sociedad de la expulsión (española y

\footnotetext{
Al-Husayn ibn Ali al poder; IBN Yusuf, Al-Mašra' Al-Malakī, vol. 2, pág. 77, y XimÉnez, Discurso de Túnez, vol. 6, ms.9/6013, fol. 64v, 30 de junio de 1724, y vol. 7, ms.9/6014, fol. $7 \mathrm{v}, 7$ de enero de 1730 .

105 Según Levy, cofià es una peluca local, «sin duda importado por los moriscos en el siglo XVII».

106 «Copia de las tacanot Antiguas que hyizieron este K.K. Tunes a 10 de Nisan 5508 (8 avril 1748)», en Levy, La nation juive portugaise, pág. 347.
} 
portuguesa): era una minoría religiosa que vivía al margen de la mayoría, ya fuera entonces cristiana o ahora musulmana.

No obstante, tenemos que advertir que la comunidad portuguesa en Túnez, durante los siglos XVII y XVIII, pudo mejorar su situación económica y social en la sociedad tunecina debido, de una parte, a que no existía la presión de la Inquisición y, de otra, gracias a la política de acogida de los gobernadores tunecinos, que vieron en la diáspora sefardí una oportunidad económica, al tratarse de un grupo conocido en todo el Mediterráneo por el comercio y su capacidad para crear riqueza.

En el mismo marco, la mejora de la situación de los sefardíes en Túnez o su capacidad para ampliar sus límites sociales y económicos, estaba relacionada con los profundos cambios económicos y políticos que conoció el mundo a finales del siglo xv y principios del xvI; a saber, el importante auge de la economía mundial después de la llegada de Cristóbal Colón a América y los grandes descubrimientos, así como el dominio político o la superioridad de las potencias europeas sobre los países del Magreb, especialmente desde el siglo XVII.

Todos estos factores subrayaron la tradicional importancia comercial y financiera de los judíos, y especialmente de los sefardíes, que vincularon sus intereses con los de las potencias europeas, lo que propició su protección formal o informal. De este modo, la comunidad portuguesa en Túnez estuvo bajo la protección formal del Duque de Livorno o la protección informal de los consulados europeos, especialmente francés e inglés. Igualmente, la diáspora sefardí había creado una red comercial muy importante y amplia, que incluía casi todos los puertos mediterráneos de Tánger a Salónica, además de las nuevas capitales del comercio global, como Ámsterdam y Londres.

Hemos mostrado que el factor económico fue el elemento más importante en la instalación de los sefardíes en la sociedad tunecina. Pues, a pesar de las dificultades de la llegada y todo lo que sufrió la primera ola de los emigrantes de fines del siglo XV y comienzos del XVI, la pujanza económica fue crucial en la mejora de la situación de los emigrantes. La rentabilidad financiera directa o indirecta que ofrecían, hizo que los beyes tunecinos facilitaran ampliamente la instalación de los sefardíes en Túnez. A cambio, su papel económico y su riqueza permitieron que los sefardíes pasaran por alto la visión negativa inicial de la mayo- 
ría musulmana, por lo que eligieron instalarse de manera definitiva en Túnez.

Todo esto fue posible porque la sociedad tunecina era multicultural, lo que implicó que la comunidad sefardí no fuera obligada a convertirse al islam o a iniciar el camino de fusión con la mayoría. Asimismo, en relación con los tuansa (la comunidad judía local), la comunidad portuguesa debido a su especificad cultural ibérica, pudo evitar hasta la primera mitad del siglo xx la fusión con la mayoría judía local. Cuando hablamos de un modelo social de pluralismo étnico en su forma primitiva significa que, aunque la comunidad portuguesa había conservado su especificad cultural y religiosa en relación con las otras comunidades, en ningún momento fue tratada en plano de igualdad con las comunidades que formaban la mayoría musulmana ${ }^{107}$, sino siempre ha sido bajo la ley de la dhimmis, lo que imponía implícitamente un estado inferior.

Entonces, y como hemos visto arriba, la existencia de la comunidad sefardí en Túnez no fue amenazada por la mayoría musulmana, sino por la comunidad judía local que pudo fusionar la primera ola de sefardíes ${ }^{108}$, pero no la segunda. A pesar de que la comunidad portuguesa ha

107 La mayoría musulmana en Túnez de la época moderna estuvo compuesta principalmente por los turcos, los Andaluces-Moriscos, los Baldis (notables), los Jerifes (descendientes del profeta) y los autóctonos. Para más detalles sobre cada categoría, véase Francisco XImÉnez, Colonia trinitaria de Túnez (Tetuán: Tip. Gomariz, 1934) págs. 45-50.

108 Al contrario que en Túnez, la primera ola (1492-1502) de expulsados sefardíes en Marruecos y Argelia pudieron mantener su independencia respecto de las comunidades judías locales. Por ejemplo, acerca de los judíos de Argelia dice XImÉnez (Viaje de Argel, vol. 1, ms.9/6008, fol. 57v, febrero de 1719): «Hay dos linajes de judíos, unos que son naturales de esta tierra de Berbería, y estos son todos vestidos de negro con una saya que les llega cerca de los habillas, a manera de cogulla de religiosos, y un albornos negro, y como andan desclasas con solo una lchearpial que solo les cubre las puntal de los de dos pasaren Agustinon descabos en el vestidos y hacen un bonete negros en la cabeza; este es el (vestido) regular de los judíos de Berbería, aunque en otros suele a ver en el vestido alguna diferencia según las familias y la posición donde an nacido. Hay otro linaje de judíos, que han nacido y se han casado en tierra de cristiandad, y estas vienen el mismo ... que los cristianos, pues andan vestidos de misaxel y con pelucos, mui buenas, según es la ciudad de los tal el judío y según les layadan los medios. Todos estos son regularmente y Mercadexel, y hubiera algunos mui ricos, sino los defiollanan los turcos con los tributos. ... Tienen heredades algunas, sino solo sus tratos y comercio: y estos son los más de Liorna; y todos cada vez mueren donde nacen; porque 
podido mantener su ser y diferencias respecto de la comunidad judía local hasta los años cuarenta del siglo xx, no ha podido conservar su identidad ibérica, debido a las influencias que ha conocido desde la segunda mitad del siglo XVIII. Esto propició que el último vicepresidente de esta comunidad, Dr. Scialom, el médico del Bey, escribiera a las autoridades francesas en 1944 un informe detallado sobre los orígenes y la identidad de esta comunidad ${ }^{109}$. ¿Por qué la identidad de la comunidad portuguesa terminó en la primera mitad del siglo xx?

No podemos responder a esta cuestión sin comprender el cambio que ha conocido la identidad portuguesa desde casi la segunda mitad del siglo XVIII, pasando de una identidad ibérica a una identidad europea. Podemos encontrar el primer testimonio a este cambio en la tacaná de Qasmet Diar el Lham, fechada en 1741, cuando los sefardíes aceptaron oficialmente que todos los judíos que llegaban de los países europeos pasaran a ser miembros de la comunidad portuguesa. Asimismo, este cambio identitario podría relacionarse con las consecuencias que tuvo en la comunidad la invasión argelina a la Medina de Túnez en 1756, pues el cronista local tunecino Asgaiyer Ibn Yusuf, nos informa que los argelinos mataron y robaron a los sefardíes:

... han captivado (los argelinos) los cristianos y han tomado sus dineros, y los judíos y sus mujeres y sus fortunas, y han tomado los restos de los cristianos de Tabarka y sus mujeres e hijas e hijos, y los violaron y su mayoría furia fue orientada a las mujeres de los judíos y sus hijos, y la comunidad del Grana (sefardíes) y sus mujeres e hijos ${ }^{110}$.

Asimismo, y no es una visión romántica a la historia, pensamos que la "atrofia" de la identidad española de la comunidad morisca jugó un papel importante en la disminución de la especificad ibérica de la co-

siempre andan viajando de una parte a otra y de un logar a otro, sin hallarse bien en parte alguna, aunque es verdad, que en todas partes los prosiguen y son los más abancidos, de todas las naciones y sectas. Los que venían de España o de Portugal retienen la lengua y hablan tan claro español o portugués, como si hubieran nacido y se hubiera ... han exilado en estos Reyes, y lo hacen por si acaso van allá, pasa poder ... que son cristianos».

109 Hemos trabajado una copia editada de este informe en nuestro artículo: «El fin de la comunidad portuguesa en Túnez», en prensa.

110 IBn Yusuf, Al-Mašra' Al-Malakī, vol. 4, págs. 85-86. 
munidad portuguesa. Puesto que la preeminencia cultural morisca fue una de las principales razones de lo que llamamos "resurgimiento cultural de la identidad sefardí en Túnez", su decadencia hubo de reflejarse negativamente en la cohesión cultural de la comunidad portuguesa, que había sido dominada por la identidad europea. Así, el destino de los sefardíes y los moriscos se cruzó otra vez. Compartieron la persecución de la Inquisición, la conversión forzada y, luego, la expulsión y su instalación en Túnez, pero también la pérdida de muchos elementos de su identidad ibérica desde la segunda mitad del siglo XVIII y su paulatina disolución.

Recibido: $16 / 05 / 2019$

Aceptado: 07/01/2020 